\title{
A CONCEPÇÃO DE TRABALHO PARA ALUNOS E PROFESSORES DE UM CURSO TÉCNICO EM ENFERMAGEM
}

\author{
Amailson Sandro de Barros ${ }^{1}$ \\ Carlos Herold Junior ${ }^{2}$
}

\section{Resumo}

Este artigo tem com objetivo apresentar a concepção de alunos e professores de um curso técnico em enfermagem sobre trabalho. Para tanto, foram entrevistados 12 alunos e 03 professores do curso. A coleta de dados ocorreu por meio de entrevistas semiestruturadas. Os dados obtidos apontaram para uma concepção de trabalho pautada no prazer e satisfação de cuidar e como fonte de remuneração, concomitantemente relacionada à perpetuação histórica e ideológica que exige da enfermagem dedicação, obediência e desapego material. As verbalizações dos entrevistados desconsideram o embate entre capital e trabalho e a construção social e histórica da exploração da força de trabalho, mantendo fortemente o dogma da caridade na área da enfermagem. Os relatos apontaram para o duplo caráter do trabalho - relacionado ao trabalho concreto e ao trabalho abstrato e a divisão trabalho intelectual versus trabalho manual e a precarização do trabalho na área da enfermagem e na docência.

Palavras-chave: Trabalho; Marx; Técnico em Enfermagem; Alunos; Professores

\section{O DUPLO CARÁTER DO TRABALHO}

O trabalho, no seu caráter ontológico - criador de valor-de-uso, trabalho útil - é uma atividade humana transformadora, que garante a existência e reprodução da vida não só individual, mas de toda a coletividade, sendo, portanto, indispensável a qualquer forma de sociedade.

\footnotetext{
1 Doutorando em Educação. Mestre em Educação. Universidade Federal de Mato Grosso. Endereço: Boa Esperança, CEP: 78060900, Cuiabá, MT, Brasil. Endereço eletrônico: amailsonbarros@gmail.com

${ }^{2}$ Professor Doutor, Departamento de Educação Física da Universidade Estadual de Maringá (UEM). Endereço: Avenida Colombo, 5790, Jardim Universitário, CEP: 85015430 - Maringá, PR, Brasil. Endereço eletrônico: carlosherold@hotmail.com
} 
Por meio do trabalho, o ser humano age sobre a natureza e a transforma, transformando a si mesmo e aos outros (MARX, 2010). Neste processo, que envolve um constante movimento de forças naturais do corpo - braço, pernas, cabeça e mãos - o trabalho se configura, ao mesmo tempo, como origem e caminho em direção ao conhecimento, o que, por sua vez, constitui mulheres e homens como sujeitos de existência do gênero humano e construtor da história da humanidade. Esta atividade, que não é casual, mas proposital, orientada pela intencionalidade, induz o ser humano a assumir posições teleológicas, cuja característica lhe permite que construa em seu pensamento o resultado do trabalho antes mesmo que ele aconteça, diferenciando-o do trabalho animal.

Marx, no capítulo V do primeiro volume de $O$ Capital, pressupõe que o trabalho é uma atividade exclusivamente humana.

\begin{abstract}
Uma aranha executa operações semelhantes às do tecelão e a abelha supera mais de um arquiteto ao construir sua colméia. Mas o que distingue o pior arquiteto da melhor abelha é que ele figura na mente sua construção antes de transformá-la em realidade. No final do processo do trabalho, aparece um resultado que já existia antes, idealmente, na imaginação do trabalhador. Ele não transforma apenas o material sobre o qual opera; ele imprime ao material o projeto que tinha conscientemente em mira, o qual constitui a lei determinante do seu modo de operar e a qual tem de subordinar sua vontade (MARX, 2010, p. 211-212).
\end{abstract}

Nessa perspectiva, o trabalho é um ato criativo, planejado, qualificado, reflexivo e de autorrealização, que proporciona aos seres humanos a satisfação de suas necessidades e a garantia, não apenas de sua sobrevivência, mas de toda coletividade (MARX, 2010; BRAVERMAN, 1987; LUKÁCS, s/d; KUENZER, 2004). O trabalho humano, portanto, ultrapassa a mera atividade instintiva, tornando-se, assim, "a força que criou a espécie humana e a força pela qual a humanidade criou o mundo como o conhecemos" (BRAVERMAN, 1987, p. 53).

Para os autores supracitados, o trabalho é a condição básica e essencial para a manutenção e formação da vida humana, da sociedade e da cultura. Assim, pode-se falar que, por meio do trabalho, o ser humano se objetiva e se individualiza, pois, diferentemente do animal que produz apenas para satisfazer unilateralmente as necessidades imediatas, os seres humanos produzem de forma universal; isto é, o trabalho assume característica vital, no processo de desenvolvimento individual e coletivo da humanidade, pois, conforme Marx (2010), é pelo trabalho que se desenvolve as potencialidades da natureza externa e da sua própria natureza humana. $\mathrm{O}$ trabalho é um processo em que o ser humano regula e controla o seu intercâmbio material com a natureza, cuja finalidade resulta não apenas na modificação da 
BARROS, A. S.; JUNIOR, C. H.

natureza externa, como também da essência humana. O trabalho é considerado o fenômeno originário do gênero humano, não existindo fora do ser social (MARX, 2010; LUKÁCS, s/d).

Engels (1876 apud ANTUNES, 2004) considera que foi pelo trabalho que as características físicas e mentais do ser humano foram se constituindo. O autor relata que a transformação gradual da condição animal para a condição humana, primeiramente, ocorreu pelo trabalho e, depois, dele e com ele, pela palavra articulada, sendo esses os dois grandes estímulos que propiciaram a evolução do cérebro humano e os órgãos dos sentidos. Engels (idem) destaca que o trabalho ampliou os horizontes do próprio ser humano, "levando-o a descobrir constantemente novos objetos, novas propriedades, até então desconhecidas" (idem, p.15) que afastaram ainda mais as mulheres e os homens dos animais, estabelecendo o trabalho como atividade coletiva:

\begin{abstract}
Graças à cooperação da mão, dos órgãos da linguagem e do cérebro, não só em cada indivíduo, mas também na sociedade, os homens foram aprendendo a executar operações cada vez mais complexas, a se propor e alcançar objetivos cada vez mais elevados. $\mathrm{O}$ trabalho mesmo se diversificava e aperfeiçoava de geração em geração, estendendo-se cada vez a novas atividades. À caça e à pesca veio juntar-se a agricultura e, mais tarde, a fiação e a tecelagem, a elaboração de metais, a olaria e a navegação. Ao lado do comércio e dos ofícios apareceram, finalmente, as artes e as ciências; das tribos saíram as nações e os Estados. Apareceram o direito e a política e, com eles, o reflexo fantástico das coisas no cérebro do homem: a religião. Frente a todas essas criações, que se manifestavam em primeiro lugar como produtos do cérebro e pareciam dominar as sociedades humanas, as produções mais modestas, fruto do trabalho da mão, ficaram relegadas a segundo plano, tanto mais quanto numa fase muito recuada do desenvolvimento da sociedade (por exemplo, já na família primitiva), a cabeça que planejava o trabalho já era capaz de obrigar mãos alheias a realizar o trabalho projetado por ela (Engels 1876 apud ANTUNES, 2004, p. 20-21).
\end{abstract}

Marx (2010) também afirma que o trabalho, quando relacionado à acumulação de riqueza de classes antagônicas que materializam a sociedade capitalista, é fator de alienação ${ }^{3}$ e de exploração da força intelectual e manual do ser humano pelo próprio ser humano. Nesse sentido, a força de trabalho passa a ser vista, exclusivamente, como mercadoria, força e capacidade de trabalho posta em movimento através de sua venda ao capitalista pelos trabalhadores ${ }^{4}$, que a alienam por não possuir nem os meios e nem os instrumentos de produção necessários para a sua utilização.

\footnotetext{
${ }^{3}$ Ressalta-se que o trabalho alienado é pertinente às sociedades de classes antagônicas e não somente à sociedade de classe capitalista.

${ }^{4}$ Mesmo sabendo que o uso político de "a/o" ou "o/a" se faz necessário e importante diante do contexto histórico de invisibilidade do feminino por meio de uma escrita marcadamente machista e heterocentrada, optamos pela fluência de leitura e normas de coesão. Adotamos em momentos distintos deste artigo o masculino genérico gramatical e o feminino genérico gramatical, sem a intenção de sermos sexista. Lembramos ainda que as citações utilizadas estão transcritas conforme os originais, em respeito a quem escreveu os livros e artigos aqui utilizados.

Revista Reflexão e Ação, Santa Cruz do Sul, v. 24, n. 3, p.162-188, Set./Dez. 2016.
}

http://online.unisc.br/seer/index.php/reflex/index 
Sob a forma capitalista, o processo de trabalho passa a ser caracterizado como produtor de valor-de-troca, que começa "com um contrato ou acordo, que estabelece as condições da venda da força de trabalho pelo trabalhador e sua compra pelo empregador", que atua como capitalista (BRAVERMAN, 1987, p.55). A classe trabalhadora, agora sob o controle do capitalista, coisifica-se e se torna acessório no processo produtivo, configurando-se como esteio do sistema de produção da mais-valia, pois é através do trabalho humano que o capital cria valor de troca e se apodera do valor excedente do trabalho, presente no produto final.

Nessa relação, os trabalhadores ficam sem o controle de seu trabalho e sem a posse do produto que criaram. Apenas receberão um salário, aquém do valor que realmente produziram. De acordo com Marx (2010), o salário apaga toda a divisão da jornada de trabalho - trabalho necessário e trabalho excedente, trabalho pago e não pago - fazendo com que todo o trabalho apareça como trabalho pago. Trabalho necessário e trabalho excedente estão relacionados à questão do tempo de trabalho.

Ao discutir o tempo de trabalho, Marx (2010) parte de duas variações: tempo de trabalho necessário e tempo de trabalho excedente. Segundo o autor, tempo de trabalho necessário refere-se à parte da jornada de trabalho necessária à manutenção e reprodução da força de trabalho realizada pelos próprios trabalhadores, paga pelo salário. Nesse sentido, o trabalho necessário é o trabalho dispendido neste tempo. Por sua vez, tempo de trabalho excedente refere-se à parte da jornada de trabalho através do qual se tem a exploração da força de trabalho pela não remuneração dos trabalhadores nesse período de tempo. Aqui a classe trabalhadora produz um valor excedente (mais-valia) que é apropriado apenas pelo capitalista, dono dos meios de produção. Portanto, todo capitalista apropria-se de um trabalho excedente e não pago produzido pelos trabalhadores durante a jornada de trabalho, mas que aos olhos desses trabalhadores e na aparência da vida cotidiana aparece como pago.

Encobre-se, assim, a essência da exploração capitalista e o que fica aparente é que o salário pago a classe trabalhadora refere-se ao pagamento integral de sua jornada de trabalho. Essa condição torna-se a base da acumulação de capital, se entendido o fato de que o capital é trabalho acumulado e que se o capitalista pagasse realmente o que está implícito no valor da força de trabalho, seu dinheiro não se transformaria em capital.

Nesse processo, o trabalho perde seu caráter humanizador e altera a relação ser humanonatureza que, alienado, por não possuir o resultado de seu trabalho e nem por pertencer a si, passa a ser guiado pela produção de valor de troca e pelo aumento do capital de outrem. 
BARROS, A. S.; JUNIOR, C. H.

Marx (2010) observou que, com o decorrer do processo histórico, o trabalho entendido como meio pelo qual mulheres e homens se humanizam e adquirem consciência do seu ser social, gradativamente, foi se transformando em uma atividade alienante, que leva ao desaparecimento do trabalho como atividade vital humana.

Os pontos constituintes dessa inversão são demonstrados a partir da análise históricosocial do desenvolvimento do capitalismo, desde a cooperação à grande indústria. Nessa análise, Marx (2010) apresenta as bases para o surgimento da propriedade privada e lança a reflexão de que é a partir das relações de produção que se impõe a divisão técnica do trabalho, demonstrando que é também por meio delas que novas formas de relações sociais são determinadas, marcando a divisão social entre os seres humanos. O que implica, no modo de produção capitalista, a separação entre concepção e execução do trabalho, entre capital e trabalho, e a histórica divisão de classes na sociedade capitalista: uma que detém os meios de produção e outra que dispõe apenas de sua força de trabalho para venda e exploração, como base para a acumulação do capital.

Dessa forma, a apropriação privada dos meios de produção torna-se elemento essencial da alienação. A força de trabalho e o produto do trabalho passam a pertencer à outra pessoa, distinta dos trabalhadores, que vê, no trabalho, uma fonte de riqueza e de prazer, ao passo que, para a classe que (sobre)vive do trabalho, constitui-se em martírio. Interessa a essa pessoa, explorar, até o limite, a força corporal dos trabalhadores.

É nessa situação específica da sociedade capitalista que a força de trabalho aparece dotada de um caráter alienante, que adquire conotações negativas e de desvalorização entre os seres humanos, a favor de uma valorização do mundo das coisas, no qual o gênero humano se coisifica, reverte-se em mercadoria e se torna propriedade do capitalista, que a utiliza com a finalidade de produzir mais mercadorias.

Conforme Marx (2006, p.111):

\begin{abstract}
O trabalhador torna-se uma mercadoria tanto mais barata quanto maior número de bens produz. Com a valorização do mundo das coisas, aumenta em proporção direta a desvalorização do mundo dos homens. O trabalho não produz apenas mercadorias; produz-se também a si mesmo e ao trabalhador como uma mercadoria, e justamente na mesma proporção em que produz bens (Grifos do autor).
\end{abstract}

Nessa lógica, a própria relação social cotidiana adquire a forma de relação entre coisas, e o trabalho, que é exterior ao ser humano, deixa de ser atividade livre e autoconsciente, para assumir o aspecto forçado, meio para a satisfação de necessidades que garantem apenas a existência física dos trabalhadores. Por consequência, a atividade vital 
humana transmuta-se em sofrimento em vez de bem-estar, o que atesta claramente o fato de o trabalho ser uma ação que mulheres e homens buscam evitar como se evita uma peste, pois seu trabalho deixa de ser voluntário e torna-se ação imposta (MARX, 2006).

Sob o prisma da alienação, o trabalho se reverte unicamente em meio de subsistência, algo que a classe trabalhadora recorre para assegurar sua sobrevivência e beneficiar o proprietário dos meios de produção. Daí o fato de que, no capitalismo, a atividade vital passa a ser rejeitada pelos trabalhadores, que não se satisfazem e nem se reconhecem no resultado do ato de sua produção. Implica-se nesse processo que os produtos produzidos opõem-se a quem os produziu como um ser estranho e independente dos produtores. Marx (2006) explica que o ato da alienação do trabalho envolve a relação de estranhamento dos trabalhadores com a própria atividade e com o resultado do seu trabalho, que se apresenta como uma coisa estranha e que não lhes pertence. Nesse sentido,

\begin{abstract}
A alienação do trabalhador no objeto revela-se assim nas leis da economia política: quanto mais o trabalhador produz, menos tem de consumir; quanto mais valores cria, mais sem valor e mais desprezível se torna; quanto mais refinado o seu produto, mais desfigurado o trabalhador; quanto mais civilizado o produto, mais desumano o trabalhador; quanto mais poderoso o trabalho, mais impotente se torna o trabalhador; quanto mais magnífico e pleno de inteligência o trabalho, mais o trabalhador diminui em inteligência e se torna escravo da natureza (MARX, 2006, p.113).
\end{abstract}

Nesta dinâmica, a alienação e, consequentemente, o trabalho alienado, permitem a relação de exploração que se estabelece entre o capitalista e a classe trabalhadora.

Além disso, para o autor, a classe trabalhadora só se sente à vontade em seu tempo de não-trabalho, enquanto realiza ativamente suas funções animais - comer, beber, procriar - ao realizar suas funções humanas, reduz-se a um animal: "o elemento animal torna-se humano e o humano, animal" (MARX, 2006, p. 115). Ao buscar atender as necessidades do sistema capitalista de produção, com o intuito de aumentar a produtividade, a atividade do trabalho reduz as funções humanas ao nível da animalidade, cujo resultado é a desumanização e pauperização do ser humano. Conforme Marx (2006, p. 111), “o trabalhador torna-se tanto mais pobre quanto mais riqueza produz, quanto mais a sua produção aumenta em poder e extensão".

Ainda, nas palavras de Marx, o trabalho alienado inverte a relação livre do ser humano com sua atividade vital e com o seu ser, de modo que o trabalho passa a ser entendido, exclusivamente, como simples meio de sua sobrevivência. "Aliena do homem o próprio corpo, assim como a característica externa, a sua vida intelectual, a sua vida humana" 
BARROS, A. S.; JUNIOR, C. H.

(MARX, 2006, p. 117-118). A alienação do ser humano com o produto de seu trabalho implica, de forma imediata e direta, o estranhamento da espécie, a alienação em relação a si mesmo e aos outros e "o que deveria se constituir na finalidade básica do ser social - a sua realização no e pelo trabalho - é pervertida e depauperada" (ANTUNES, 2010, p. 144).

Como pontua Marx, com a alienação mulheres e homens tornam-se estranhos em relação ao gênero humano.

Já que o trabalho alienado aliena a natureza do homem, aliena o homem de si mesmo, o seu papel ativo, a sua atividade fundamental, aliena do mesmo modo o homem a respeito da espécie; transforma a vida genérica em meio da vida individual. Primeiramente, aliena a vida genérica e a vida individual; depois, muda esta última na sua abstração em objetivo da primeira, portanto, na sua forma abstrata e alienada (MARX, 2006, p. 116).

Ademais, a alienação,

[...] não se expõe apenas no resultado, mas também no processo da produção, no seio da própria atividade produtiva. Como o trabalhador poderia estar numa relação alienada com o produto da sua atividade, se não se alienasse a si mesmo no próprio ato da produção? O produto constitui apenas resumo da atividade da produção. Em consequência disso, se o produto do trabalho é a alienação, a produção em si tem de ser alienação ativa - a alienação da atividade e a atividade da alienação. Na alienação do objeto do trabalho, resume-se apenas a alienação da própria atividade do trabalho (MARX, 2006, p. 114).

O jogo de palavras, realizado por Marx, no excerto acima, para demonstrar que o produto do trabalho é resultado de uma alienação ativa, demonstra que a alienação é algo concomitante ao processo de produção capitalista. O ser humano se depara com um produto estranho a si no processo de trabalho, justamente por estar alienado de si mesmo. Nesse sentido, tem-se que a síntese do desenvolvimento da produção é o resultado do trabalho alienado e meio pelo qual os trabalhadores se alienam. Para Marx (2006, p.118), a alienação do homem realiza-se, inicialmente, na relação entre os seres humanos, e, portanto, na relação do trabalho alienado, "cada homem olha os outros homens segundo o padrão e a relação em que ele próprio, como trabalhador, se depara."

Ao analisar o trabalho alienado e a relação de alienação do ser humano consigo mesmo e com os outros, Marx (2006) discute que toda autoalienação manifesta-se na relação que o ser humano estabelece entre os outros seres humanos, consigo mesmo e com a natureza.

Por consequência, o homem, por meio do trabalho alienado, não só produz a sua relação com o objeto e com o ato de produção como com homens estranhos e hostis, mas produz ainda a relação dos outros homens com a sua produção e com o seu produto, e com a relação entre ele mesmo e com os outros homens. Do mesmo modo 
como ele cria a sua produção como sua desrealização, como a sua punição, e o seu produto como perda, como produto que não lhe pertence, da mesma maneira cria o domínio daquele que não produz sobre a produção e o respectivo produto. Assim como aliena a própria atividade, também confere a um estranho a atividade que não lhe pertence (MARX, 2006, p. 119).

Entretanto, se as transformações que se operam na forma como a pessoa se relaciona com o trabalho são resultados de processos históricos produzidos pela própria ação humana, estas são passíveis de mudanças e de resistências, podendo se consolidar em elementos formadores de uma nova ordem social. A razão disto é que o trabalho é um processo histórico e mutável, determinante e determinado do conjunto de relações estabelecidas pelo modo de produção da existência humana (KUENZER, 2004).

Kuenzer (2004) destaca que, embora ocorra a negação da humanidade pelo caráter explorador do trabalho, reside no ato do trabalho toda a realização da humanidade. Ou seja, mesmo submetido à reprodução de valor de troca, o ser humano continua sendo um ser consciente e criativo, embora sua consciência e sua capacidade criadora não se exercitem de forma plena, devido à exploração inerente da produção de valor para o capital.

Segundo Marx (2006), a superação do trabalho alienado poderia ocorrer por meio da socialização revolucionária da riqueza produzida pelo e no trabalho, estabelecendo, assim, relações sociais mais igualitárias, que trouxessem em seu bojo a valorização do ser humano e não do capital; que manifestassem o reconhecimento entre as pessoas e a superação da propriedade privada, acarretando o fim da dominação do capital sobre o trabalho e a classe trabalhadora.

Para o autor, a alternativa apresentada para a superação da propriedade privada seria o comunismo:

O comunismo é a eliminação positiva da propriedade privada como autoalienação humana e, desta forma, a real apropriação da essência humana pelo e para o homem. É, deste modo, o retorno do homem a si mesmo como ser social, ou melhor, verdadeiramente humano, retorno integral, consciente, que assimila toda a riqueza do desenvolvimento anterior. O comunismo como naturalismo inteiramente evoluído = humanismo, como humanismo inteiramente desenvolvido = naturalismo, estabelece a resolução autêntica do antagonismo entre o homem e a natureza, entre o homem e o homem. É a verdadeira solução do conflito entre a existência e a essência, entre a objetivação e a autoafirmação, entre a liberdade e a necessidade, entre o indivíduo e a espécie. É o decifrar do enigma da História e está consciente de ele próprio ser essa solução (MARX, 2006, p. 138).

O que Marx (2006) manifesta por meio da eliminação da propriedade privada é a possibilidade de o homem eliminar de si a alienação a que se encontra submetido na produção 
BARROS, A. S.; JUNIOR, C. H.

capitalista, integrando-se ao trabalho de forma não alienada, compreendendo a si mesmo, historicamente, como um ser genérico e social. “A supressão da propriedade privada constitui, deste modo, a emancipação total de todos os sentidos e qualidades humanas." (idem, p. 142).

\section{METODOLOGIA}

A presente pesquisa foi realizada junto a um curso Técnico em Enfermagem, inserido no contexto da rede pública de ensino do Estado do Paraná, ofertado na modalidade subsequente, em um colégio localizado na região centro-sul do Estado. Participaram desta pesquisa 15 sujeitos, sendo 12 alunos, matriculados entre o primeiro e o quarto semestre, e 03 professores supervisores de estágios. A escolha pelos sujeitos ocorreu de forma aleatória, após apresentação do tema de pesquisa nas turmas e convite direcionado aos alunos e professores por um dos pesquisadores.

Os dados foram coletados através de entrevistas semiestruturadas e categorizados a partir da análise de conteúdos. Justifica-se a escolha pela modalidade de entrevista semiestruturada pelo fato de que a mesma permite ao entrevistador liberdade para desenvolver e explorar as perguntas com maior flexibilidade, na direção que considerar adequada, formulando-as de maneira que seja entendida pelo entrevistado e esclarecendo-as sempre que oportuno (GIL, 1996).

As entrevistas foram realizadas individualmente e previamente autorizadas pelos participantes, após leitura, aprovação e assinatura do termo de consentimento livre e esclarecido, que garantiu a participação voluntária na pesquisa e anonimato.

A abordagem adotada, para dar conta das indagações levantadas e guiar os procedimentos acima descritos, baseou-se na pesquisa qualitativa.

A opção pela pesquisa qualitativa deu-se ao seu caráter funcional, pois oferece uma compreensão particular do fenômeno estudado. Ao focar na especificidade do objeto, a pesquisa qualitativa busca a compreensão detalhada dos significados da realidade vivida pelos entrevistados, sem cair em generalizações (RICHARDSON, 1999).

O referencial teórico adotado para esta pesquisa está pautado no materialismo histórico dialético, desenvolvido por Marx e Engels.

Ao assumir o materialismo histórico como horizonte teórico, procurou-se utilizar as lições deixadas por Marx ao analisar a sociedade capitalista do século XIX e criticar a ciência política na forma como, até então, relacionava trabalho, riqueza e sociedade. 
Em um dos poucos momentos em que falou explicitamente dos procedimentos metodológicos que guiavam suas análises, Marx (1977), no Prefácio à Contribuição da Crítica à Economia Política, oferece algumas ideias essenciais que formam o fio condutor do materialismo histórico dialético. Segundo o autor, a primeira consideração a ser levada em conta reside no entendimento de que, na produção social de sua existência, os seres humanos, independentemente, de sua vontade, entram em relações de produção que condicionam o seu processo de vida social, política e espiritual. Marx também entende que o movimento das forças produtivas não ocorre sem apresentar contradições com as relações de produção.

Ao possibilitar que as contradições existentes em uma determinada realidade sejam percebidas e pautadas nas relações de produção como fatores ordenadores da construção histórica das sociedades, o materialismo histórico possibilita que o pesquisador problematize a aparência de seu objeto de estudo, colaborando para que ele seja posto em evidência a partir da totalidade social. O indispensável às investigações reside nessa condição de entender a especificidade de uma determinada realidade com questões históricas mais amplas.

\section{APRESENTAÇÃO E DISCUSSÃO DOS RESULTADOS}

\subsection{Perfil do grupo de estudantes participantes da pesquisa}

A faixa etária do grupo de estudantes que participaram desta pesquisa está situada entre 18 até 40 anos, sendo que a maioria (09 estudantes) que possui idade entre 25 anos a 40 anos. Em relação à caracterização do sexo dos entrevistados, 10 são do sexo feminino e 02 do sexo masculino. Em relação ao total de alunos regularmente matriculados no curso, no momento da coleta de dados, o quantitativo era de 114 alunos, sendo 99 alunos do sexo feminino e 15 do sexo masculino. O que aponta a enfermagem como campo de trabalho eminentemente feminino (GERMANO, 1993; RIZZOTTO, 1999; OGUISSO, 2007; RIBEIRO, 2009). Tais estudos endossam, também, que a participação das mulheres, no mercado de trabalho, historicamente, se fez e ainda se faz via profissões que exploram as capacidades femininas para o cuidado e o ensino, no caso a enfermagem e o magistério.

Segundo as respostas do grupo de estudantes, dada a observação de que o quantitativo de mulheres matriculadas no curso é superior ao número de homens, a explicação para a grande procura de mulheres pelo Curso Técnico de Enfermagem está relacionada à ênfase ao 
BARROS, A. S.; JUNIOR, C. H.

aspecto de cuidado e natureza assistencial do trabalho de enfermagem, que se aproxima dos cuidados maternais e a uma extensão do lar, cujas características marcantes são coerentes ao exercício de amor e doação

As entrevistas atestam uma seletividade baseada nessas qualidades, tidas como naturais ao gênero feminino; portanto, seria a enfermagem uma atividade digna para ser exercida pelas mulheres. Dessa forma, permanece a visão histórica e idealizada, que cria uma relação altruísta entre o exercício de enfermagem com o trabalho materno e missionário, visão que atua inclusive como forma de valorizar socialmente a profissão:

O instinto da mulher é cuidar. É por isso que a mulher se identifica mais com a enfermagem, porque a enfermagem é o ato de cuidar. $\mathrm{O}$ ato de amar e o ato de cuidar (E. 02).

Cabe mais ao universo feminino ajudar. Os homens são mais durões no modo de olhar, no modo de pensar. As mulheres, pelo fato do instinto materno, tendem mais a ajudar. Enfermagem mesmo é auxílio, é ajuda. É mais do universo feminino. Geralmente, o homem não se põe no lugar do outro (E. 03).

Homem já não se envolve muito, porque dizem que é gay. Até lá no posto tinha um homem só, tinha dois, três enfermeiros. Um foi embora porque era cidade pequena, outro ficou e agora tem um só. Ele é muito bonito. Ele disse que as meninas falam que por ele ser enfermeiro, então é gay. Eu acho que para homem não combina a enfermagem. Porque é um serviço mais delicado, que mulher tem mais paciência. Homem já não tem, homem tem a mão pesada. Até para fazer uma injeção, né? A mulher é mais calma. Fala mais calmo, a mulher sabe levar conforme a situação. O homem é mais explosivo (E. 09).

De outro lado, chama-se à atenção para a questão do preconceito manifesto em relação à sexualidade dos trabalhadores homens que exercem a função do cuidado na área de enfermagem. Nesse sentido, repousa sobre a divisão sexual do trabalho a ideia de que o cuidado não é exercício profissional para homens. Nas palavras de Lopes (1996 apud WAINBERG, 2004), no imaginário social, o trabalho de enfermagem ainda é considerado uma desvalorização e afronta à identidade social e sexual dos homens que nele atuam.

Para Lopes e Leal (2005, p.108-109), a predominância feminina em todos os níveis da área de enfermagem segue condicionada aos princípios organizadores da produção capitalista que colocam a preferência por um tipo ideal de profissional baseado nos atributos característicos ao gênero e aos valores simbólicos e vocacionais que influenciam o recrutamento majoritariamente feminino na área. Entretanto, a despeito de algum grau de masculinização no exercício de enfermagem, as autoras identificam uma inclinação dos homens para determinados setores da ação profissional, a partir dos atributos que sugerem o que é trabalho de homem e o que é trabalho de mulher. 
... alguns preferem mais socorristas, já é da área deles mesmo (E. 01).

Vou tentar o socorrista, vou tentar primeiro o socorrista, depois uma faculdade de enfermagem (E. 03).

Em relação à ocupação profissional dos estudantes, 11 participantes dos discentes atuam profissionalmente em áreas afins ao curso Técnico de Enfermagem. A renda familiar dos entrevistados variou entre um salário mínimo a dois salários mínimos. De um total de doze participantes discentes, 07 têm rendimentos até um salário mínimo brasileiro e 05 até dois salários.

Segundo as verbalizações do grupo de discentes, a busca pelo Curso Técnico de Enfermagem está relacionada ao discurso da constante especialização, da possibilidade de transferência de um setor de trabalho para o outro, utilizando-se de um caminho mais rápido de formação profissional e como alternativa compensatória ao ensino superior.

Chama a atenção, também, o fato de que essa escolha pelo ensino técnico é vista pelo grupo de discentes participantes desta pesquisa como uma oportunidade dada a quem "tem vontade de continuar estudando". Entretanto, sabe-se que essa escolha é muito mais complexa e carrega em si uma relação histórica e social contraditoriamente construída, que se desenvolve através da divisão social do trabalho e faz com que uma sociedade dividida em classes obtenha distintos tipos de saber, que corroboram para o desenvolvimento do modo de produção, a estratificação social e a própria divisão do trabalho.

Pode-se perceber, pelos depoimentos, que a modalidade de ensino técnico vem se mantendo, ao longo de sua história, como possibilidade de educação para aquelas pessoas que se encontram em situação socioeconômica menos favorecida, fator esse que potencializa as dificuldades de entrada no ensino superior. Isto acontece pelo fato das pessoas entrevistadas não possuírem uma renda capaz de mantê-las apenas estudando ou pela condição de não se sentirem preparados intelectualmente para prestarem um vestibular em instituições públicas e/ou pagar uma faculdade particular. Demonstram, com isso, que mecanismos econômicos e educacionais se integram e previamente agem no sentido de direcionar pessoas que ocuparão basicamente profissões cuja mão de obra será mais barata ao capital e aquelas que ocuparão profissões mais elitizadas.

Não tinha a condição de fazer uma faculdade, nem um vestibular, nem nada. Daí, apareceu um curso assim, eu aproveitei a oportunidade (E. 01). 
BARROS, A. S.; JUNIOR, C. H.

Eu sou gráfico, teve uma época que eu ganhei muito bem, depois meu salário decaiu. Na época que eu ganhava bem eu deixei de... Podia ter feito uma faculdade e não fiz. Hoje talvez esteja tentando recuperar o tempo perdido, mas também por gostar (E. 03).

Quem tem dezoito, dezenove anos, tem uma vida pela frente, pode fazer uma faculdade, tudo. Agora, a gente que já está meio... tem que correr contra o tempo (E. $06)$.

O grupo de discentes também estabelecem uma relação direta entre educação e garantia de melhoria das condições de vida e de trabalho, na qual prevalece a concepção de que o investimento na educação profissional aumenta a possibilidade de empregabilidade e a possibilidade de elevar a renda do trabalhador. Converte-se a educação em condicionante de garantia de emprego e produção. De acordo com as entrevistas coletadas, a posse do conhecimento teórico e a certificação profissional, enquanto instância instrumental permitem mais facilmente a inserção e manutenção dos trabalhadores no mercado de trabalho.

Além disso, verificou-se que há uma dificuldade estrutural de obtenção desse conhecimento, manifesto nos esforços necessários, nos arrependimentos de abandono dos cursos e na pressão social que responsabiliza as próprias pessoas pelos seus méritos e fracassos, legitimando e reforçando a desigualdade social.

Eu acho que as pessoas nunca deveriam parar de estudar. Eu digo isso porque eu senti na pele. Eu parei de estudar, casei e fiquei parada, e me arrependo muito. Podia estar melhor financeiramente (E. 07).

Eu abandonei tudo e fiz supletivo. Até por causa deste curso. [...] Fiz o supletivo correndo tudo, porque eu não estudei ano por ano como tinha que ser o certo, né? Fui até uma altura porque a gente morava no interior. Eu tinha que trabalhar nisso, tinha que trabalhar naquilo e acabei abandonando. Eu não fiquei muito na escola (E. 09).

Comparando os dados referentes à renda familiar e à faixa etária da maioria dos sujeitos de pesquisa percebe-se, nesse particular, que a modalidade subsequente de ensino técnico de enfermagem, oferecido pela instituição, atende a demanda de um público adulto-jovem, pertencente à classe trabalhadora, que estava, em sua maioria, afastada da escola. O grupo de estudantes é oriundo do ensino médio cursado em escolas públicas, seja pelo sistema regular de ensino ou por meio da modalidade da Educação de Jovens e Adultos (EJA).

\subsection{Perfil do grupo de docentes entrevistados}

Em relação aos professores entrevistados, num total de três profissionais, todos possuem experiência de mais de cinco anos como profissionais de enfermagem e de cinco a 
seis anos como supervisores de estágios, coincidindo o tempo de docência em sala de aula com o de supervisão de estágios.

Assim como observado no perfil do grupo de estudantes, dois docentes (P.01 e P.03) relataram que a escolha pelo curso superior em enfermagem ocorreu devido à atuação e aproximação com o ambiente hospitalar, exercendo, nesse caso, funções de nível médio. Ao abordar o caminho que os conduziu ao trabalho de enfermagem, esses dois entrevistados relataram que iniciaram a carreira profissional como atendentes de enfermagem:

$\mathrm{Na}$ época, era o magistério que você tinha que fazer ou a área da saúde. Eu me identifiquei muito mais na área da saúde, eu queria trabalhar no hospital. Eu comecei a trabalhar no hospital, no serviço de copa, carregando alimentação, levando alimentação para os pacientes. Depois disso fui indo, né? (P. 01).

Eu comecei a fazer o atendente com 17 anos, na verdade eu fui ajudar no hospital e na época eu solicitei para a enfermeira se eu podia acompanhar alguns procedimentos. Eu fui puxar maca. A gente era o profissional que colocava o paciente na maca e tirava da maca (P. 03).

O sujeito P.02 conta que a escolha pelo Curso ocorreu como segunda opção no vestibular, após algumas tentativas frustradas para o Curso de Farmácia. Segundo P.02, a escolha "pela enfermagem foi assim no grito. Eu era sempre farmácia, farmácia, farmácia. Não deu farmácia, tentei enfermagem. Passei. Resolvi cursar e descobri que era isso que eu queria.” (sic). Nesse depoimento, pode-se observar que o processo de escolha por esta ou aquela profissão está também muito ligado a ideia de que o sujeito estabeleceu uma relação entre o seu perfil pessoal com o perfil profissional, para sentir-se realizado e ciente de que fez a escolha certa. Entretanto, infere-se, a partir dessa mesma verbalização que, no sistema capitalista, há a utilização de mecanismos classificatórios, a exemplo do vestibular, para direcionar as escolhas profissionais entre aqueles que supostamente receberam oportunidades iguais de escolarização, ajustando-os às estruturas existentes e encobrindo o fato de que fatores econômicos e históricos interferem na escolha profissional e que esta, embora seja um processo individual, mantém forte relação social.

O grupo de professores informou possuir especialização, com ênfase em Saúde da Família (P.03) e Saúde Coletiva (P.02 e P.03). A idade dos sujeitos está acima dos trinta anos.

Observa-se que, do grupo de professores, duas pessoas declararam exercer diariamente, além da docência, outras atividades remuneradas, caracterizando tripla jornada de trabalho, pois trabalham no período diurno como enfermeiros e, à noite, como professores. P.01 relatou ser aposentado do serviço de enfermagem. 
BARROS, A. S.; JUNIOR, C. H.

Para o grupo entrevistado, a busca pelo trabalho docente se explica pela possibilidade de aumento de renda e pela vocação. Porém, a fala de P.02 expressa, também, que a busca pelo trabalho docente é resultado de uma saturação do mercado de trabalho em enfermagem, mostrando, com isso, que, para alguns dos profissionais de enfermagem, uma das opções para a entrada no mundo do trabalho é via educação.

[...] eu tinha que aumentar a questão financeira e por isso eu fiz a inscrição no núcleo. Não é que eu estou arrependida. Estou gostando muito e depois eu me aposentei como enfermeira e hoje estou como professora (P. 01).

[...] o que me levou foi esse querer transmitir o pouco que eu sei, né? Porque a gente vai morrer e não vai saber tudo. Mas o pouco que eu sei para tentar passar para os alunos da melhor forma possível. A gente vê que para o profissional de enfermagem hoje o campo está muito saturado (P. 02).

Foi na faculdade que eu consegui descobrir que eu tinha uma vocação, porque a gente sempre participava de palestras, cursos e trabalhando em estágios de escolas de primeiro grau, creches, cursos de terceiro grau, trabalhava com palestras, com teatros e ali eu descobri que eu poderia ser professor. Foi uma coisa bem interessante na minha vida. Hoje é mais um trabalho que eu gosto. Além de enfermeiro, a docência me chama a atenção (P. 03).

Ainda, de acordo com P.01, responsável pela coordenação do curso, muitos professores, que formam o corpo docente, são contratados pelo Processo Simplificado de Seleção (PSS). Num total de dezoito professores, seis são professores pertencentes ao quadro próprio e efetivo do magistério e doze foram contratados via PSS. Verifica-se, portanto, que mais de $50 \%$ dos professores atuam sem concurso público, submetidos a contratos temporários e flexíveis. Esta realidade não difere da realidade de outro grande contingente de profissionais de educação, nas suas diversas especialidades e graus de ensino (fundamental, médio e superior), que também são contratados, no Estado do Paraná, via PSS. Os efeitos dessa forma de gerir a educação ultrapassam a precarização das relações contratuais do trabalho docente e sua proletarização e se manifestam também em descaso com os alunos, seja pelo atraso na contratação de professores, o que prejudica o início do ano letivo, e em coisas básicas, como falta de materiais para uso em aulas e durante os estágios. A lógica evidenciada é de que o Estado busca realizar o máximo com o mínimo de recurso possível.

O Estado quer que se mantenha o curso, mas em questão de material não está sendo providenciado a nível de Estado. A gente está tendo muita dificuldade para o nosso material que a gente utiliza lá no hospital: luvas, máscaras, tudo. Em cima disso tem uma cobrança também, né? Então, é bem, né? Outra questão é o PSS. Este ano o PSS prejudicou o início das aulas, começando tudo meio quebrado. Algumas disciplinas vão e outras ficam. O PSS não sendo liberado fica só o estatutário, que é o mínimo de professores. Somos em seis agora e hoje o curso mantém dezoito professores. Veja quantos são do PSS. Até a gente conseguir organizar já era quase 
final de março. Então, veja bem, começou dia 08 de fevereiro para chegar quase no final de março e ainda esperando professor para assumir alguns estágios (P. 01).

Para Milani e Fiod (2008), essa forma de contratação colabora para manter sob pressão os professores efetivos e desfaz o sentido de coletividade do magistério. As autoras observaram uma preocupação da categoria calcada na ideia de que há, fora do mercado de trabalho, um contingente enorme de pessoas que estão dispostas a ingressar no mercado de trabalho por salários inferiores aos recebidos pelos docentes concursados.

Isso tem causado sentimentos de desconfiança no relacionamento entre os docentes efetivos e os recém-contratados ou celetistas. Não se forma um coletivo, o que dificulta as lutas comuns. De um lado, estão os professores efetivos, de outro os substitutos/temporários. E, nas mobilizações de reivindicação por melhores condições de trabalho, por melhores salários e por menor carga horária, apenas os professores efetivos se engajam no movimento (MILANI e FIOD, 2008, p. 78).

Nessa direção, o grupo de docentes participante desta pesquisa, embora seja formado por professores concursados e efetivos, convivem diretamente, através de seus colegas temporários, com um processo caracterizado por Kuenzer (2004) de "exclusão includente", por meio do qual o mercado formal exclui o trabalhador para reincorporá-lo em formas mais precárias de contratação, seja com salários mais baixos ou através de empresas terceirizadas, prestando os mesmos serviços.

A flexibilização dos contratos de trabalho dos professores PSS impõe exigências ao trabalhador contratado que se vê, muitas vezes, obrigado a ministrar aulas de disciplinas para as quais não está devidamente preparado. Outro aspecto, evidenciado nas entrevistas, diz respeito à rotatividade de professores, via PSS, que acarreta, na percepção dos entrevistados, prejuízos à formação dos alunos:

A gente está tendo dificuldades com uma professora que entrou agora. Ela foi chamada num período mais tarde, né? O PSS que chamou. Então, entrou tarde. Ela não tinha o material pronto, ela acabou de se formar. Ela nem sabia a matéria que ela iria dar. Daí a gente está tendo um pouco de dificuldade. Lá no estágio a professora já pediu algumas coisas que a gente ainda não viu aqui (E. 07).

Eu acho que este ano eles pegaram professores com pouca experiência, recémformados, que não têm experiência na prática para dar aula teórica. Eles tiraram... na verdade esse negócio não depende muito do colégio, depende muito daquele negócio de pegar as aulas pelo PSS, este que é o problema, né? (...) E nós demos um pouquinho de azar porque o nosso professor que pegou não tem prática nenhuma. Nenhuma mesma. Ele vai coloca o data-show e vai lendo ali e não explica para a gente. Ficamos completamente perdidos. A gente sabe pelo que a gente estuda na apostila e morre ali. Na verdade, não é culpa do colégio, né? Eu culpo essa coisa de quem pegar aula primeiro. (...) Então, é essa a maior dificuldade que a gente está tendo no curso. Eu mudaria a questão da contratação dos professores. Eu daria 
BARROS, A. S.; JUNIOR, C. H.

chance para quem está há mais tempo no ramo, não para quem acabou de se formar, porque eles não têm prática nenhuma para ensinar (E. 10).

\title{
3.3 Concepção de trabalho para os entrevistados:
}

\subsubsection{Da satisfação à precarização e exploração da força de trabalho}

Os relatos dos grupos de estudantes e do grupo de docentes engendram a concepção de trabalho pautada no prazer de cuidar, na autorrealização e como fonte de remuneração.

\begin{abstract}
A gente sem trabalho não é nada. Não só pelo fato do dinheiro. Claro que você trabalha porque precisa do dinheiro. Também não tem aquela coisa piegas de a gente dizer que não trabalha por dinheiro, porque a gente trabalha, mas a importância maior é você ver o resultado do teu trabalho. Você ver a pessoa bem, ver a pessoa sorrindo (E. 05).
\end{abstract}

Satisfação, amor, prazer. Tudo isso. Eu faço o que eu gosto. O trabalho, no meu conceito, é tudo na vida de uma pessoa, porque traz dignidade. Imagine a pessoa sem serviço, sem trabalhar. O que é feito? Que satisfação vai ter na vida? Trabalho é dignidade para o ser humano (E. 08).

Gratificação. Porque, na verdade, financeiramente o técnico de enfermagem não é atrativo. Mais pela satisfação de você fazer o que você gosta (E. 03).

Das pessoas entrevistadas, 04 consideraram o salário dos profissionais como incompatível às responsabilidades e atividades desenvolvidas pela enfermagem. Todos revelaram que a maior motivação para a realização do trabalho de enfermagem advém do fato de serem reconhecidos pelas ações que desenvolvem e pela satisfação em ajudar aqueles que necessitam, ou seja, os doentes, o que remete à perpetuação histórica e ideológica que exigia das pessoas que praticavam a enfermagem uma extrema dedicação, obediência e desapego material, em benefício de outrem. Mantém-se, com esse discurso, o dogma da caridade entre os profissionais, como forma de superar as adversidades do dia a dia do trabalho, e que parece anular a ideia de que a remuneração pelo trabalho exercido é, também, resultado do longo embate entre capital e trabalho e uma construção social e histórica.

Apesar de o trabalho de enfermagem ser remunerado, a ideologia presente nas verbalizações, de certa maneira, desconsidera a interferência do sistema produtivo capitalista nas ações do cuidado como forma de aumentar a produção (principalmente em instituições privadas) e encobrir, inclusive, a exploração da força de trabalho desses profissionais. Em meio a essas considerações, persiste o fio condutor do trabalho alienado e sua interferência no sentido social e pessoal do trabalho para os grupos participantes desta pesquisa. No conjunto 
das verbalizações, revela-se a contradição entre o motivo para retornar ao estudo e a motivação para o trabalho em enfermagem.

É possível verificar, nas falas dos dois grupos (discentes e docentes), o trabalho no seu caráter de estranhamento, ou seja, na ideia de que o ser humano trabalha não apenas pelo prazer da atividade que exerce e muito menos para se realizar enquanto homem, mas "porque precisa do dinheiro" (E. 05).

No resgate das palavras de Marx (2006, p112), na situação específica da sociedade capitalista, "a realização do trabalho surge de tal modo como desrealização que o trabalhador se invalida até a morte pela fome”.

\subsubsection{Trabalho intelectual versus trabalho manual}

Pode-se considerar que a desvalorização do trabalho de enfermagem está relacionada, também, ao seu histórico de dependência ao saber médico, a uma questão de gênero e à desvalorização do trabalho manual em relação ao trabalho intelectual.

Nesse sentido, a dependência a um saber intelectual, a desqualificação histórica do trabalho feminino e do trabalho manual agem no sentido de delimitar os espaços hierárquicos do trabalho hospitalar. Sabe-se, por exemplo, que, na linha da hierarquia, a medicina é superior a enfermagem, esta aos técnicos e estes, por sua vez, superiores aos auxiliares. Para Pires (1998), a organização do trabalho de enfermagem segue uma hierarquia baseada no grau de ensino e na qualificação profissional, muito ligada à gestão taylorista e a divisão do trabalho em tarefas.

Assim sendo, a forma como a enfermagem se encontra estruturada coloca os trabalhadores de ensino superior em funções de coordenação da equipe, ficando com trabalhos complexos e burocráticos de assistência ao paciente, associada, por exemplo, ao registro do trabalho executado pela equipe. Enquanto isto, a classe de trabalhadores de ensino médio (técnicos e auxiliares de enfermagem) realiza cuidados funcionais e rotineiros. "A organização do trabalho exige dele que apenas cumpra bem as tarefas que lhe foram designadas" (PIRES, 1998, p. 190).

O enfermeiro faz a parte de assistência e administração. O técnico faria toda a questão prática, que é o trabalho com o paciente. $\mathrm{O}$ auxiliar ficaria no suporte aos cuidados integrais de higiene, assistência na alimentação e medicação fora dos setores de alta complexidade (p. 01). 
BARROS, A. S.; JUNIOR, C. H.

Observa-se, portanto, que a organização do trabalho de enfermagem segue a lógica da divisão de tarefas, de forma estratificada e controlada, colocando, de um lado, uma minoria pensante, que exercerá o trabalho intelectual e, de outro, uma maioria executora do trabalho manual, marcada por ações repetitivas, monótonas, um trabalho "meio robótico" (P.03), o que prescreve o parcelamento do trabalho como algo muito representativo da sociedade, que se organiza em uma divisão de classes, que centraliza as relações sociais a partir da dominação e subordinação de uns para como os outros. Esta dominação, que se torna cada vez mais sofisticada a cada nova redefinição do padrão de acumulação capitalista, tem contado, com o apoio da educação, quando se discute sua revalorização como forma diretamente ligada à produção e obtenção de trabalhadores com capacidades que atendam as exigências da lógica capitalista.

Por essa perspectiva, a educação não se isenta da subordinação aos interesses econômicos de reprodução do capital, cujo reflexo é visto, claramente, na divisão de conteúdos e na gestão do processo educativo. Verifica-se que o modelo de educação profissional destinada à classe trabalhadora é alinhado historicamente ao como fazer, ao pragmatismo.

Desse modo, a enfermagem de ensino superior, por receber, supostamente, uma educação científica e tecnológica mais elaborada, passa a ser considerada mais competente para exercer o comando e direção do trabalho de assistência realizado pela equipe de nível técnico e auxiliar, atuando como uma espécie de gerente, controlando horários e escalas de serviços.

O trabalho do auxiliar de enfermagem é um trabalho mecanizado, é um trabalho meio robótico, porque você aprende a fazer as coisas mecanicamente, é uma parte assim mecanizada mesmo. Quando você assume como técnico de enfermagem, já muda a questão do trabalho. Você passa para uma visão mais holística. Você vai saber o porquê da medicação, o que pode acontecer, qual a reação alérgica. $O$ enfermeiro é aquela pessoa que pensa de verdade, é aquela pessoa que supervisiona (P.03).

Entretanto, P.03 parece não perceber que este poder decisório da enfermagem de nível superior é historicamente limitado, em muito, pelas ordens médicas, o que demonstra que, embora possuindo certa autonomia para avaliação das necessidades do paciente, a enfermagem mantém-se subordinada ao trabalho médico, fazendo com que a lógica de separação entre o saber e o fazer permaneça de uma categoria a outra, delimitando as possibilidades de ação. 
Não se pode deixar de observar que o sistema educacional, através de suas práticas educacionais diferenciadas, proporciona aprendizagens análogas às relações sociais de produção, direcionando conteúdos conforme o esperado da função que o aluno desempenhará no processo produtivo.

Na verbalização de P.03, a ideia de que a educação cumpre com a responsabilidade e a função de formar trabalhadoras e trabalhadores, conforme as diferenças exigidas pelo mundo do trabalho são expostas quando o entrevistado discorre sobre a divisão entre aqueles que terão como base uma educação mais abrangente do processo de cuidar e aqueles que ficaram limitados a realizar ações mecânicas.

A organização das tarefas da equipe de enfermagem a cargo de um(a) profissional com curso superior colabora de certa forma, também, para as exigências de aprendizagem da classe de profissionais de ensino médio. Afinal, para a ocupação desses postos de trabalho, o que se leva em conta é muito mais o conhecimento técnico adquirido num espaço de tempo muito menor, quando comparado com o da qualificação técnica universitária, como se fosse suficiente gostar do que se faz, para tornar-se apto para o trabalho.

Por outro lado, espera-se que tais profissionais demonstrem iniciativa para o trabalho e empatia, características consideradas vitais na relação do cuidado com o paciente. Essas questões, que se colocam como essenciais ao trabalho, da enfermagem, são vistas também como possibilidades de a/o profissional obter acesso a conhecimentos técnicos e informações mais gerais para o atendimento e realização de seu trabalho, contrapondo-se, de certa forma, à fala que afirma que esta classe trabalhadora apenas "executa" ou que "não pensa de verdade". A iniciativa do próprio indivíduo torna-se fator fundamental que define o bom profissional:

Um bom técnico é aquele que o alvo é o paciente. Aquele que tem a iniciativa, que a exclusividade seja o cuidar do paciente. Hoje a gente tem, infelizmente, alunos que estão ali realmente pelo emprego. É aquele que chega ali e vê a necessidade do paciente. [...] A enfermagem cuida, o médico cura. Para curar tem que ter alguém para cuidar e esse é o técnico, o auxiliar, o enfermeiro, que tem que fazer. Então, é aquele que realmente se dedica, e tem prioridade em cima do paciente. Tem que cuidar do paciente (P.01).

Você tem que gostar do que faz, você tem que se colocar no lugar do paciente. Pode ser a gente um dia ali, pode ser um da família da gente. Eu acho muito importante o trabalho do técnico (E.05).

As exigências, para se definir a excelência profissional, trazem, em seu bojo, a concordância com as novas demandas do mercado de trabalho, por pessoas que se posicionem 
BARROS, A. S.; JUNIOR, C. H.

profissionalmente de forma polivalente, criativa, flexível e com sólida estrutura emocional para se adaptar às mudanças do mundo do trabalho. Em consonância ao atual estágio do capitalismo flexível, as verbalizações sinalizam para a valorização das características individuais como fatores relevantes à realização do trabalho.

Como bem observou Deluiz (2001), interessa ao capitalismo flexível não só a posse dos saberes disciplinares escolares ou técnico-profissionais, mas os componentes não organizados da formação, como as qualificações tácitas ou sociais e a subjetividade para resolver problemas e enfrentar imprevistos na situação de trabalho. A classe trabalhadora, nesse sentido, passa a ser educada para ser capaz de desenvolver habilidades concretas, explicitadas a partir das tarefas inerentes a cada posto de trabalho.

Ao se observar, no conjunto de verbalizações desta pesquisa, a função da enfermagem de nível superior dentro da equipe de enfermagem, pode-se perceber que essa atua no sentido de solucionar dúvidas e tornar mais ágeis os trabalhos dos outros profissionais que a compõe:

Seria a enfermeira chefe dali, que sempre está por lá e vê o que precisa ser feito pelos técnicos, os auxiliares. Eu já vi bastantes auxiliar e técnicos que, com dúvida, vem até ela. Daí ela diz que você vai fazer isso, isso, isso... Até hoje eu estava no posto de enfermagem e ela deu risada: - Toma conta que eu já volto. Ligou um técnico do centro cirúrgico, que eu não lembro o que ele precisava, porque ia ter cirurgia depois do almoço, mas tinha que ser ela que tinha que dar permissão para ele pegar, não sei se era medicamento ou o que era. Então eu acho que parte dela, para daí os técnicos e auxiliares, né? Até na limpeza, pelo que eu entendi, é ela que... porque eu vi uma hora ela dizer para as meninas que tinha infecção não sei onde (E. 12).

A separação entre trabalho intelectual e trabalho manual, no âmbito da enfermagem, não deixa de ser sentida pelos dois grupos entrevistados como sendo, também, a responsável pela desvalorização da categoria, quando comparada ao trabalho da medicina. Neste processo, a medicina mantém o domínio do conhecimento sobre a saúde e a doença. Isso lhe confere um caráter mais intelectual e o poder de delegar atividades manuais a outras categorias profissionais de área da saúde. O aspecto evidenciado de que o pensar ficou para aquela e o fazer para esses pode ser percebido no depoimento a seguir:

A equipe dos técnicos, junto com a equipe de enfermagem, se dão bem, se acertam, conseguem conversar e, se você tem alguma dificuldade, você recebe ajuda. Agora quando você chega frente a frente com um médico, você fala qualquer coisinha ele... não dá muita saída. Por exemplo, vou citar o exemplo de hoje. Hoje, quando a gente fez a medicação corretamente para a pressão, né? E estava muito elevada e a gente esperou quase duas horas e a gente estava vendo os sinais vitais frequentemente e não baixava. Foi um enfermeiro e falou para o médico e ele nem deu bola. Foi uma técnica, ele não falou nada. Aí ficou para mim. Eu cheguei: - Olha doutor, desculpa incomodar, mas novamente a paciente não está passando bem e a gente já medicou e 
já subiu novamente a pressão. A gente viu os sinais vitais e ela não está passando bem. Mesma coisa que você não tivesse falado nada. Ele levantou, chamou outro paciente e não falou mais nada. Disse assim: - Eu já mediquei! Vocês já deram o medicamento, então tudo bem, vai passar. Tipo assim, não tem uma ligação. Parece que conta muito o nível de estudo, quanto mais estudo se tem menos bola se dá e assim por diante. A questão do eu posso e eu falo e vocês obedecem. Para mim, a única coisa que me deu a entender foi isso. A questão dele saber e você não ter o direito nenhum de dar opinião porque ele é o médico. Tem uma dificuldade de você interagir com o médico muito grande. Não só um, dois, técnicos de enfermagem ou enfermeiros que passaram por isso hoje, então para mim ficou isso (E. 11).

A análise das entrevistas também revelou que a enfermagem vem buscando a construção de teorias sistematizadas em princípios científicos para, assim, legitimar seus saberes e modos de agir diante das diversas especialidades que compõem o trabalho em saúde:

\begin{abstract}
Antigamente, quando a gente entrou, era um nível muito diferente. Quem era médico era considerado meio Deus e agora na verdade tem vários profissionais de enfermagem fazendo mestrado, fazendo doutorado, fazendo teses, fazendo essas teorias, e todos já conseguem se aproximar. Na verdade, agora não é mais médico e enfermeiro que trabalham na área da saúde, mas sim uma equipe multidisciplinar e que todos têm o seu valor. O médico não consegue trabalhar sem ter o enfermeiro, sem ter o terapeuta, e outros profissionais da área da saúde que precisa também. $\mathrm{O}$ enfermeiro também não consegue trabalhar sem o médico. Então, a melhor coisa que tem, graças a Deus, é que começou a dar uma nivelada. E os profissionais estão sendo tratados iguais. A única deficiência, a única diferença é em valores financeiros. Agora tem profissionais que se impõem. Não é só o médico que sabe tudo. Tem que mostrar o que aprendeu na faculdade, na pós-graduação e nos trabalhos que fez na pós-graduação. Tudo isso serve de conhecimento. Agora se o enfermeiro não tem questão de evoluir, não faz curso, terminou a faculdade e terminou o mundo para ele, se torna difícil competir com o pessoal da medicina. Porque aí o médico sempre vai ter a palavra final e o enfermeiro sempre vai ter que abaixar a orelha para ele (P. 03).
\end{abstract}

Nesse sentido, verifica-se que a enfermagem busca revisar seu conhecimento e prática, ao reconstruir teorias e institucionalizar seu saber, em prol de uma autonomia que assegure um atendimento individual e coletivo, que supere o modelo biomédico e a certeza adquirida de que este é o mais eficaz para a solução dos problemas de saúde.

\title{
3.4 Trabalho multidisciplinar na área da saúde
}

O grupo de estudantes e o grupo de docentes evidenciam a prevalência da ideia de trabalho multidisciplinar na área da saúde como positividade no processo de apreensão do objeto saúde-doença-cuidado. Nesta forma de organizar o trabalho e a educação, recorre-se aos vários conhecimentos para intervir e entender uma determinada situação. Entretanto, os diversos saberes e práticas ficam restritos as ações sequenciais de cada profissional diante do 
BARROS, A. S.; JUNIOR, C. H.

cuidado, sem cooperação direta e troca de informações. Cada categoria profissional continua realizando seu trabalho separadamente, ao invés de, conjuntamente, planejar ações unificadas na busca de soluções a determinadas situações. Peduzzi (2001) observa que, no trabalho multidisciplinar, a equipe é vista com agrupamento de agentes e não como equipe de integração de trabalho, sendo caracterizada pela fragmentação das ações sobre o objeto comum. Entende-se que, pela peculiaridade de seu objeto, processo saúde-doença, o trabalho em saúde comportaria ações interdisciplinares, tendo na equipe multidisciplinar o fundamento para essa realização.

A interdisciplinaridade superaria, em muito, o modelo médico hegemônico, que reduz o processo saúde-doença a questões unicamente biológicas, em detrimento das considerações socioeconômicas, históricas e psicológicas. Esta interdisciplinaridade estaria, inclusive, em consonância à proposta adotada pelo SUS, por meio da Lei Orgânica $n^{\circ}$ 8.080/1990, que defende um atendimento integral das necessidades de saúde de um grupo ou indivíduo.

De acordo com a Lei $\mathrm{n}^{\circ} 8.080 / 1990$, são fatores determinantes e condicionantes de saúde, entre outros, a alimentação, saneamento básico, meio ambiente, trabalho, educação, lazer e moradia. Ademais, essa lei defende que os níveis de saúde da população expressam a organização social e econômica do País sendo, portanto, inadmissível que se lance uma visão reducionista, de cunho predominantemente biológico, aos problemas de saúde.

$\mathrm{Na}$ realização de um atendimento interdisciplinar, amplia-se a perspectiva de diálogo complementar entre os diferentes profissionais e seus diferentes modos de perceber o processo saúde-doença.

Ademais, se, por um lado, a enfermagem de nível superior envolve-se na busca por um conhecimento teórico mais elaborado de suas práticas para, assim, tornar-se mais autônoma, essa abordagem parece não ser levada em consideração quando se pensa na formação dos profissionais de enfermagem de nível médio. Isto demonstra a reprodução de relações ideológicas que introduzem o fracionamento, a hierarquia e a disciplina, sob o enfoque de diferentes níveis de técnicas de um mesmo processo de trabalho que, no caso da enfermagem, é o cuidar. Tal fato se torna evidente com a valorização da avaliação da destreza manual do futuro técnico de enfermagem nas atividades de estágio, como bem demonstra a verbalização de P.01, logo abaixo.

A destreza manual, como que ele faz, como que ele dilui uma medicação, como que ele vai aplicar, como que ele vai se relacionar com o paciente na hora de fazer a medicação. Essa questão da avaliação da destreza manual, do preparo da medicação, de fazer a higiene é o peso maior. Vale dois pontos. É um item de dois pontos 
porque é aquilo que ele vai fazer na vida dele como técnico de enfermagem. É isso que ele vai fazer (P.01).

\section{CONCLUSÃO}

A análise dos dados indicou que o trabalho, atividade humana por excelência, é vista pelos entrevistados através dos limites resultantes do amplo processo de produção. Isso não permite que estudantes e docentes participantes da pesquisa enxerguem o processo de produção social pelo trabalho, vivenciando, sem terem uma consciência elaborada, a prática laboral reduzida ao traço meramente subjetivo, reprodutivo e subordinado às estruturas organizacionais. Isso revela a histórica adaptação dos futuros profissionais a um determinado modelo de trabalho na enfermagem que se construiu na sociedade capitalista a partir do século XIX, proximamente relacionado às transformações dos processos produtivos do capitalismo de forma geral.

Nesse contexto, a perpetuação da ideologia do modelo de profissionalização na área da enfermagem que, historicamente, separa a trabalho manual versus trabalho intelectual, mostra-se ainda presente na fala dos entrevistados, mas não é criticamente por eles compreendida. Por este viés e distanciados de uma reflexão sobre a interferência das relações sociais capitalistas na formação profissional, os entrevistados seguem tradicionalmente formados a partir dessa dissociação.

Também foi possível perceber, na realização deste estudo, que a enfermagem está socialmente marcada pela divisão sexual do trabalho, o que ficou explícito a partir das verbalizações que a legitimam como uma profissão feminina, que encontra justificativa no fato de que suas atividades práticas demandam delicadeza, cuidado, bondade e submissão. $\mathrm{O}$ trabalho de enfermagem é tido como uma vocação e/ou dom.

Por enfim, sob o domínio do valor de troca, a concepção de trabalho é quantificada e atrelada ao trabalho realizado em troca de salário.

Observa-se, neste sentido, a dicotomia gerada pelos próprios seres humanos no caráter ontológico do trabalho, que se manifesta na ruptura entre trabalho manual e trabalho intelectual e que concorre para a manutenção das relações sociais desiguais e de dominação de uma classe sobre a outra, bem como a exploração da compra da força de trabalho, posta a venda pela classe trabalhadora, por se constituir único meio de sua sobrevivência. 
BARROS, A. S.; JUNIOR, C. H.

Por este viés, foi possível observar que a concepção de trabalho se mantém distanciada de uma reflexão sobre as interferências das relações socais capitalistas no processo de constituição da força de trabalho na área de enfermagem.

Os resultados demonstraram também a fragmentação histórica e não naturalizante do trabalho na área da enfermagem e sinalizaram a possibilidade de superação dessa fragmentação através do trabalho interdisciplinar, sob o ideário da integralidade, ação ainda a ser conquistada.

\title{
THE CONCEPTION OF NURSING WORK BY STUDENTES AND TEACHERS
}

\section{FROM A TECHNICAL COURSE}

\begin{abstract}
This article aims at presenting the conception of work envisioned by students and teachers from a technical course on nursing. For that end, we interviewed 12 students and 03 teachers from the course. The data was collected through structured interviews. The data obtained pointed to a concept of work relied on pleasure and satisfaction for caring, as well as source of remuneration, which is related to the ideological background perpetuated that associates nursing to dedication, obedience and material detachment. The speech of the participants disregards the shock between capital and labor and the social construction and historical exploitation of the workforce, keeping strongly the dogma of charity in the field of nursing. The reports pointed to the dual character of the work which comprises the abstract and concrete conceptions, leading to a division between intellectual labor versus manual work and precarization of labor in nursing and teaching.
\end{abstract}

Keywords: Work; Marx; Nursing Technician; Students; Teachers

LA CONCEPCIÓN SOBRE EL TRABAJO PARA ESTUDIANTES Y PROFESSORES EN CURSO TECNICO DE ENFERMERÍA 


\section{Resumen}

Este artículo tiene como objetivo presentar la concepción que estudiantes y profesores de un curso técnico en enfermería presentan sobre el trabajo en la área. Para hacer la pesquisa, se entrevistó a 12 estudiantes y 03 profesores del curso. Los datos fueron recolectados en entrevistas semiestructuradas. Los datos apuntan a un pensamiento sobre el trabajo guiado por el placer y la satisfacción de la atención ofrecida y la fuente de remuneración en forma concomitante relacionada con la perpetuación histórico e ideológico que requiere la dedicación de enfermería, la obediencia y desprendimiento de lo aspecto material. La verbalización de los entrevistados ignorara el choque entre el capital y el trabajo y la construcción social e histórica de la explotación de la fuerza de trabajo, manteniendo firmemente el dogma de la caridad en el campo de la enfermería. Los informes señalaron el carácter dual del trabajo - relacionado con el trabajo concreto y trabajo abstracto y la división del trabajo intelectual en comparación con el trabajo manual y la precariedad del trabajo en la enfermería y la enseñanza.

Palabras-clave: Educación Continua; Enseñanza; Servicios de Integración Docente Asistencial; Sistema Único de Salud

\section{REFERÊNCIAS}

ANTUNES, Ricardo (Org.). A dialética do trabalho: Escritos de Marx e Engels. São Paulo: Expressão popular, 2004.

ANTUNES, Ricardo. Adeus ao trabalho? Ensaio sobre as metamorfoses e a centralidade no mundo do trabalho. 14. ed. São Paulo: Cortez, 2010.

BRASIL. Lei $n^{\circ}$.8.080, 19 de setembro de 1990; dispõe sobre as condições para a formação, proteção e recuperação da saúde, a organização e o funcionamento dos serviços correspondentes e dá outras providência. Disponível em: <http:

//portal.saude.gov.br/portal/arquivos/pdf/lei8080.pdf > Acesso em: 23 jan. de 2011

BRAVERMAN, Harry. Trabalho e capital monopolista: a degradação do trabalho no século XX. 3. ed. Rio de Janeiro: Editora Guanabara, 1987.

DELUIZ, Neise. O modelo das competências profissionais no mundo do trabalho e na educação: implicações para o currículo. Boletim Técnico do Senac, Rio de Janeiro: Senac, v. 
BARROS, A. S.; JUNIOR, C. H.

27, n.3. set/dez, 2001. Disponível em: <http://www.senac.br/boletim.htm>. Acesso em: 04 fev. de 2011.

GERMANO, Raimunda Medeiros. Educação e ideologia da enfermagem no Brasil. 3. ed. São Paulo: Cortez, 1993.

GIL, Antônio Carlos. Como elaborar projetos de pesquisa. 3. ed. São Paulo: Atlas, 1996.

KUENZER, Acacia Zeneida. Sob a reestruturação produtiva, enfermeiros, professores e montadores de automóveis se encontram no sofrimento do trabalho. Revista Trabalho, Educação e Saúde, Rio de Janeiro: Fundação Oswaldo Cruz, v.02, n. 1, p.239-265, março, 2004.

LOPES, M. J. M.; LEAL, S. M. C. A feminização persistente na qualificação profissional da enfermagem brasileira. Cadernos Pagu, Campinas: Unicamp, n.24, p.105-125, jun. 2005.

LUKÁCS, G. O Trabalho. Tradução Prof. Ivo Tonet (Universidade Federal de Alagoas), a partir do tex to II Lavoro, primeiro capítulo do segundo tomo de Per uma Ontologia dell'Essere Sociale (p.1 a 80), s/d.

MARX, Karl. Manuscritos econômicos-filosóficos. São Paulo: Martin Claret, 2006. 2010. O capital: critíca da economia política. 27. ed. Rio de Janeiro: Civilização Brasileira, 1977. . Prefácio de contribuição à crítica da economia política. Martins Fontes, São Paulo,

MILANI; N. Z.; FIOD, E. G. M. Precarização do trabalho docente nas escolas públicas do Paraná (1990-2005). Roteiro, Joaçaba: Unoesc, v.33, n.1, p.77-100, jan./jun. 2008.

OGUISSO, Taka (org.). Trajetoria histórica e legal da enfermagem. 2. ed. Barueri, São Paulo: Manole, 2007.

PEDUZZI, Marina. Equipe multiprofissional de saúde: conceito e tipologia. Revista de Saúde Pública. São Paulo: Universidade de São Paulo, v.35, n,1, p.103-109, fev. 2001. http://dx.doi.org/10.1590/S0034-89102001000100016

PIRES, Denise. Reestruturação produtiva e trabalho em saúde no Brasil. São Paulo: Confederação nacional dos trabalhadores em seguridade social - CUT; Annablume, 1998.

RIBEIRO, Antônio César. O trabalho do enfermeiro: a relação entre o regulamento, o dito e o feito, no cotidiano hospitalar. 2009. 219 f. Tese (Doutorado em Enfermagem) Universidade Federal de São Paulo, São Paulo.

RICHARDSON, Roberto Jerry. Pesquisa social: métodos e técnicas. 3. ed. São Paulo: Atlas, 1999.

WAINBERG, Sara. Experiências e vivências de auxiliares de enfermagem do sexo masculino no exercício de uma profissão majoritariamente feminina. 2004. 62 f. Dissertação (Mestrado em Psicologia Social) Universidade Federal do Rio Grande do Sul.

Data de recebimento: $11 / 07 / 2012$

Data de aceite: 04/05/2016 